Article

\title{
Characterizations of Biomasses for Subsequent Thermochemical Conversion: A Comparative Study of Pine Sawdust and Acacia Tortilis
}

\author{
Gratitude Charis ${ }^{1, *(1)}$, Gwiranai Danha ${ }^{1(1)}$ and Edison Muzenda ${ }^{1,2}$ \\ 1 Department of Chemical, Materials and Metallurgical Engineering, Botswana International University of \\ Science and Technology, Palapye P Bag 016, Botswana; danhag@biust.ac.bw (G.D.); \\ muzendae@biust.ac.bw (E.M.) \\ 2 Department of Chemical Engineering Technology, School of Mining, Metallurgy and Chemical Engineering, \\ University of Johannesburg, P O Box, 17011, Doornfontein 2094, Johannesburg, South Africa \\ * Correspondence: gratitude.charis@studentmail.biust.ac.bw; Tel.: +267-72-483-242
}

Received: 14 March 2020; Accepted: 22 April 2020; Published: 8 May 2020

check for updates

\begin{abstract}
The bioenergy production potential from biomasses is dependent on their characteristics. This study characterized pine sawdust samples from Zimbabwe and acacia tortilis samples from Botswana using conventional and spectrometry techniques. The ultimate analysis results for pine were $45.76 \%$ carbon $(\mathrm{C}), 5.54 \%$ hydrogen $(\mathrm{H}), 0.039 \%$ nitrogen $(\mathrm{N}), 0 \%$ sulphur $(\mathrm{S})$ and $48.66 \%$ oxygen (O) and, for acacia, were $41.47 \%$ C, 5.15\% H, 1.23\% N, $0 \% \mathrm{~S}$ and $52.15 \%$ O. Due to the low N and S in the biomasses, they promise to provide cleaner energy than fossil-based sources. Proximate analysis results, on a dry basis, for acacia were $3.90 \%$ ash, $15.59 \%$ fixed carbon and $76.51 \%$ volatiles matter and $0.83 \%, 20 \%$ and $79.16 \%$, respectively, for pine. A calorific value of $17.57 \mathrm{MJ} / \mathrm{kg}$ was obtained for pine, compared with $17.27 \mathrm{MJ} / \mathrm{kg}$ for acacia, suggesting they are good thermochemical feedstocks. Acacia's bulk energy density is five times that of pine, making it excellent for compressed wood applications. Though the ash content in acacia was much higher than in pine, it fell below the fouling and slagging limit of $6 \%$. In pyrolysis, however, high ash contents lead to reduced yields or the quality of bio-oil through catalytic reactions. Fourier transform infrared spectrometry indicated the presence of multiple functional groups, as expected for a biomass and its derivatives.
\end{abstract}

Keywords: biomass; characterization; lignocellulosic; bioenergy

\section{Introduction}

\subsection{Background and Purpose of the Study}

A sustainable biomass-to-bioenergy conversion requires adequate knowledge of both the supply capacity and quality of the biomass [1]. The utilization of a biomass for bio-energy is limited by the biomass' low bulk and energy density, resulting in increased transportation and handling costs per unit energy potential or produced [2]. Most biomasses also have high moisture and mineral contents, along with wide-ranging, nonuniform physical and chemical properties [3]. These physical and chemical properties affect biomass-to-bioenergy conversion processes and the entire value chain, as further described in Table 1. Therefore, it is crucial to assess the quality of a biomass by evaluating these physicochemical properties and their corresponding effects on the thermochemical conversion process and quality of products. Such characterization results would aid the design and development of necessary biomass pretreatment methods that improve its quality, efficiency of the conversion process and quality of products. 
The properties of lignocellulosic biomasses widely vary with the diversity of the tree species. Even for the same species from different geographical origins, there can be notable differences that could be caused by the different climatic and soil conditions, as demonstrated by several studies made on pine biomass in various forms [4-8]. For instance, studies of pine biomass from Spain and Canada yielded different results for the ultimate analysis, with those produced in Spain giving a lower threshold carbon $(\mathrm{C})$, hydrogen $(\mathrm{H})$, nitrogen $(\mathrm{N})$, Oxygen $(\mathrm{O})$ and sulphur $(\mathrm{S})$ composition of $48.3 \%$, $5.2 \%, 0.16 \%, 46.2 \%$ and $0.14 \%$, compared with those grown in Canada yielding $49.0 \%, 6.4 \%, 0.14 \%$, $44.45 \%$ and $0.01 \%$, respectively $[7,8]$.

The main motivation of this study is to investigate the different types of biomass materials from different geographical locations. Thus, we chose Acacia tortilis, a "new" biomass yet to be explored for thermochemical processes, and made a comparison with the widely studied pine. Even so, characterizing the Zimbabwean pine will give specific facts about the feedstock in this particular geographical location, while providing a point of reference for comparison with acacia. Moreover, the pine studied in this research is in the form of sawmill residues, whose properties will also vary with different storage conditions. This further justifies the need to characterize this feedstock from specified locations.

The properties of the two biomasses are useful in predicting the most efficient logistic, pretreatment and biomass-to-bioenergy conversion methods and conditions [9]. Ultimately, the characterization of feedstocks would help explain experimental biomass-to-bioenergy conversion profiles and how product yields and quality relate to biomass properties. This knowledge will be used for subsequent pyrolysis experiments in this study. Regardless, the characterization study was generalized to include the effects of biomass properties on other thermochemical biomass-to-bioenergy conversions, such as combustion, torrefaction and gasification.

\subsection{The Significance of Biomass Characterisation for Bioenergy Applications}

Biomass physicochemical properties are relevant in many ways at various points of a biomass process flow, especially for upstream activities and midstream conversion stages [10]. Figure 1 shows the process flow steps affected by the physicochemical properties of a biomass.
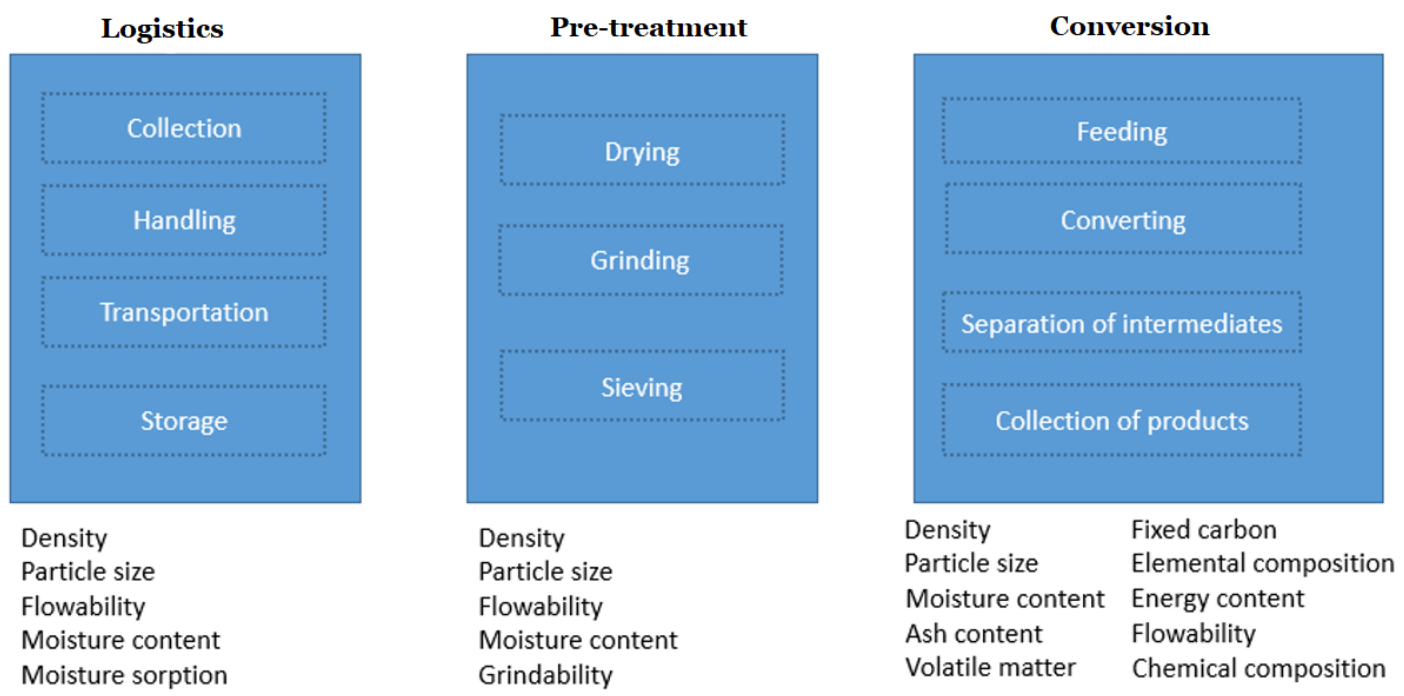

Figure 1. Relevant physicochemical properties of a biomass at different process flow steps. Reproduced with permission from Cai et al. [9], Review of physicochemical properties and analytical characterization of lignocellulosic biomass; published by Elsevier, 2017.

Álvarez-Álvarez et al. [1] investigated the thermochemical properties of four short-rotation woody coppices to determine their energy production potential, with an emphasis on characterization as a critical requirement for the efficient and sustainable exploitation of biomass resources. Tumuluru et al. [11] and 
Mani et al. [12] examined the grinding energy requirements and physical properties of hammer-milled cereals and energy crops. They found that physical properties like the moisture content and initial particle size affected grinding energy requirements, while bulk and tapped density affected the storage requirements, size of the handling systems and conversion efficiency. Several studies have examined the efficacy of particular pretreatment methods such as torrefaction, chemical or biological treatments in enhancing specific desirable fuel or physical properties [11-14]. Biomass characterization has been used to determine the effect of such a pretreatment on physicochemical and thermal properties. In Table 1, we present a summary discussion on the relevance of selected properties to logistic and unit processes of the biomass process flow chart as provided in the literature.

Table 1. Selected physicochemical properties and their relevance to various process flow steps.

\begin{tabular}{|c|c|c|}
\hline Physicochemical Property & Relevance/Significance & Literature \\
\hline Density (particle, bulk and tapped) & $\begin{array}{l}\text { Useful for design of storage, handling and transportation facilities. Bulk and tapped } \\
\text { density also help determine flowability and compressibility of biomass through the } \\
\text { Carr and Hausner indices. }\end{array}$ & {$[1,9,11]$} \\
\hline Compressibility & $\begin{array}{l}\text { Useful for the design of storage, handling and feeding facilities. Higher } \\
\text { compressibility shows that more feedstock can be stored or transported in } \\
\text { a fixed volume. }\end{array}$ & {$[9,15]$} \\
\hline Ash content & $\begin{array}{l}\text { Indicates a potential risk of fouling or slagging during combustion or gasification. } \\
\text { Higher ash/mineral content indicates a higher risk for fouling and slagging in } \\
\text { combustion and gasification, the critical value being } 6 \% \text {. Ash also catalyzes the } \\
\text { breakdown of pyrolysis vapors into water, carbon dioxide and other simpler } \\
\text { molecules. This reduces yields and the quality of bio-oil. }\end{array}$ & {$[13,16,17]$} \\
\hline $\begin{array}{l}\text { Elemental (CHNS-O) } \\
\text { composition }\end{array}$ & $\begin{array}{l}\text { Determines conversion efficiency and product composition. Significant N and S } \\
\text { contents indicate a polluting effect. }\end{array}$ & [13] \\
\hline $\begin{array}{l}\text { Functional group composition } \\
\text { (as investigated by FTIR) }\end{array}$ & $\begin{array}{l}\text { Useful in predicting the dominant behavior of a substance and its conversion } \\
\text { products by analyzing the reactive groups. For instance, the dominance of aliphatic } \\
\text { functional groups in a compound can be a good indication of the good fuel } \\
\text { properties of liquid derivatives from a feedstock. }\end{array}$ & {$[13,17]$} \\
\hline Fuel/Thermal properties & $\begin{array}{l}\text { Indicates the thermochemical conversion efficiency and heating capabilities of fuel } \\
\text { (especially in combustion or exothermic phases). }\end{array}$ & {$[13,16]$} \\
\hline
\end{tabular}

${ }^{1}$ CHNS-O-carbon, hydrogen, nitrogen, sulphur, and oxygen. FTIR: Fourier-transform infrared spectroscopy.

\section{Materials and Methods}

The physicochemical characterization carried out on the biomasses in this study comprised proximate, ultimate, thermogravimetric and functional group analyses. Compositional analyses were used to determine the fuel potential of the feedstock. The thermal and fuel properties, in terms of heating value, were measured using a bomb calorimeter. Physical properties, namely the particle, bulk and tapped densities, were also determined. The physicochemical, thermal and fuel properties indicate how a feedstock behaves during a thermochemical conversion and the expected energy output from the process. On the other hand, physical properties generally affect the storage and handling logistics.

\subsection{Sources of Biomasses Studied}

Two lignocellulosic biomass feedstocks from Zimbabwe and Botswana were considered for comparative purposes, given their potential bioenergy benefits to these two nations. Pine sawdust (Pinus patula spp.) is a waste product from sawmilling activities in Manicaland Province, situated on the eastern part of Zimbabwe. Sawdust and wood shavings represent the most unutilized waste fractions from the sawmill operations, accumulating at approximately 70,000 tonnes per annum [18]. Heaps of such waste fractions are scattered all over Manicaland Province, marring its aesthetic appeal and posing various ecological threats, including fire, greenhouse gas emissions and wood residue leachate 
that has high concentrations of dissolved organic matter $[19,20]$. The valorization opportunities that have been identified for the sawmill waste include combined heat and power generation from pyrolysis and the gasification/co-gasification of liquid and solid fuels and wood-engineered products [18].

Acacia tortilis is an encroacher species that is debushed from rangelands and urban circles of Botswana. Together with other encroachers, it has significantly reduced the size of quality rangeland available for both domestic and wild animals in Botswana. It costs the local and national government millions of pulas annually, since bush control programs have to be carried out to regenerate rangeland grass or improve the aesthetic appeal in villages, towns, cities and highways [21]. However, drought-resistant Acacia tortilis quickly rejuvenates after debushing, encouraged by overgrazing. Charis et al. [21] noted that the bush encroachment situation in Botswana was similar to that of Namibia, a country that is successfully valorizing its vast encroacher bush in charcoal, heat and power-generation schemes. They recommended that some of the ideas and other novel schemes, encompassing pyrolysis and gasification of the biomass, be adopted in Botswana.

\subsection{Compositional Analysis and Thermal Properties}

\subsubsection{Thermogravimetric Analyzer}

The LECO thermogravimetric analyzer (TGA) 701 (Leco TGA, St Joseph, MI, USA) was used to determine the ash composition, inherent moisture content (MC), fixed carbon (FC) and volatile matter (VM) present in the pine and acacia samples. The TGA was set to comply with the American Society for Testing and Materials (ASTM) E1131-03 and to analyze the MC, ash, VM and FC compositions as described under the ensuing subheadings [22]. The instrument was programmed to perform all these tests at various temperatures. The LECO TGA 701 automatically weighed the samples, giving real-time changes in mass. For the Acacia tortilis, the samples were placed in two categories, "with bark" and "debarked", to determine if there would be a significant difference in the TGA profiles and proximate composition for the two groups of acacia biomasses.

\section{Moisture Content}

Samples of 1-3 g were put into the automatic sampling containers in the TGA. The exact sample masses were then determined using the automatic balance and, subsequently, ramped the TGA at $10{ }^{\circ} \mathrm{C} / \mathrm{min}$ to $105{ }^{\circ} \mathrm{C}$ to remove all moisture. The drying process was carried out in a dynamic atmosphere of nitrogen gas until a constant "moisture mass" was achieved; then, the TGA automatically engaged the next stage.

Volatiles Content

The TGA was set at $550{ }^{\circ} \mathrm{C}$ for volatization, such that, after removing the moisture, the temperature automatically adjusted to the set point within $10 \mathrm{~min}$. Volatization occurred in an inert environment of nitrogen gas until a near-constant mass was achieved.

Ashing

After burning off the volatiles, the lids were removed from the samples, and the biomass samples were reheated to $550{ }^{\circ} \mathrm{C}$ in an oxygen-rich environment. The mass that was lost during the ashing process was the fixed carbon, which reacted with oxygen.

\subsubsection{Ultimate Analysis}

The ultimate analysis was conducted using the Flash $2000 \mathrm{CHNS}$ elemental analyzer (ThermoFisher Scientific, Waltham, MA, USA). The biomass samples were first weighed in the sample containers with the equipment's auto-sampler system, then introduced into the combustion reactor. After combustion in an oxygen-rich environment, the gases given off were carried by a helium flow past a copper-filled layer, through gas chromatography (GC) column where the combustion gases were separated and 
detected by a thermal conductivity detector [23]. The oxygen content was calculated from the difference between the cumulative $\mathrm{C}, \mathrm{H}, \mathrm{N}$ and $\mathrm{S}$ percentage composition and $100 \%$.

\subsubsection{Fourier Transform Infrared Spectroscopy (FTIR) Analysis}

The biomass samples were grounded using a hammer-chopper mill fitted with a screen size of $3 \mathrm{~mm}$. The mill product was further ground and sieved to obtain samples of less than 1-mm particle size. An infrared (IR) scan was then conducted for the wavenumber of 4000 to $500 \mathrm{~cm}^{-1}$ for the underflow samples from the sieves using a Vertex70v FTIR spectrometer (Bruker, Ettlingen, Germany) [24].

\subsubsection{Calorimetry}

The high heating value (HHV) of the biomasses was determined using a bomb calorimeter, Bomb CAL2K-2 (Digital Data Systems, Randburg, South Africa), according to DIN 51,900 T3 standards for the "testing of solid and liquid fuels-determination of gross calorific value". A crucible with a sample of about 1.00-g biomass was placed in the calorimeter. The bomb was then closed and filled with oxygen pressurized to 30 bars. The sample was covered in an adiabatic jacket along with some known quantity of water. It was then ignited electrically, resulting in a rise of the water temperature, enabling automatic evaluation of the HHV of the sample. The calorimeter was calibrated using benzoic acid.

Table 2 summarizes the standard analyses conducted on the biomass and instruments that were used.

Table 2. Standard compositional and thermal analyses and the instruments used. HHV: high heating value and TGA: thermogravimetric analyzer.

\begin{tabular}{llll}
\hline Test Conducted & Standards Used/Reference & Instrument & Manufacturer \\
\hline Proximate analysis & ASTM E1131-03 & LECO TGA 701 & LECO, St Joseph, MI, USA \\
Ultimate (CHNS-O) & {$[23]$} & Flash 2000 CHNS elemental analyzer & ThermoFisher Scientific, Waltham, MA, USA \\
Vertex70v FTIR & {$[24]$} & Vertex70v FTIR spectrometer & Bruker, Ettlingen, Germany \\
HHV & DIN 51,900 T3 & Bomb CAL2K-2 & Digital Data Systems, Randburg, South Africa \\
\hline
\end{tabular}

\subsection{Physical Properties}

The MC, in particular, was measured "as received" and also after solar drying for at least three weeks. All the compositional and calorimetric characterizations were only done for dried biomasses in the condition they would be when introduced into the thermochemical conversion system. This criterion would also make the two cases comparable; otherwise, a significant difference in moisture contents would lead to a bias in many properties of the biomasses.

\subsubsection{Particle Density}

Since a pycnometer was not available, we measured the particle density using relatively large biomass particles whose dimensions could be measured according to the method used by Lam et al. [15]. For pine sawdust, particles with a rectangular geometry were chosen, while cylindrical twigs were more suitable in the Acacia tortilis case. In both cases, the particles where further filed on the ends to correctly simulate the relevant geometry. The length, width and height $(L \times W \times H)$ of the rectangular sawdust particles were measured, while only the length and diameter $\left(L\right.$ and $\left.D_{p}\right)$ of the Acacia tortilis cylindrical particles where determined. Vernier caliper, accurate to the nearest $0.1 \mathrm{~mm}$, was used to measure all the dimensions. The mass of the particles was measured using a scale accurate to the nearest $0.01 \mathrm{~g}$. Particle density $\left(D_{p}\right)$ was determined as:

$$
D_{p}=\frac{M_{p}}{V_{p}}
$$

where $M_{p}$ was the mass and $V_{p}$ the volume of the cylindrical particle. The particle densities of three particles were obtained and used to calculate the mean as the final particle density of the biomasses. 


\subsubsection{Bulk and Tapped Density}

The bulk density for the selected size classes was obtained through sieving. The size ranges $(\mathrm{x})$ that were used are:

- Mixed (as-received basis) — Sawdust comes with a mixed size, while any first grind of Acacia tortilis similarly would contain a mixed size range. Since this mixed size is often handled or stored before further pretreatment or conversion, it is useful to determine the bulk and tapped density for this category. A sieve of $10 \mathrm{~mm}$ was used for the 1st grind of Acacia tortilis.

- Five millimeters $<x \leq 7.1 \mathrm{~mm}, 3.35 \mathrm{~mm}<\mathrm{x} \leq 5 \mathrm{~mm}$ and $1.70 \mathrm{~mm}<\mathrm{x} \leq 3.35 \mathrm{~mm}$-The pine sawdust and Acacia tortilis particles were subjected to a sieve classification using 9-mm, 7.1-mm, 5-mm, $3.35-\mathrm{mm}$ and $1.70-\mathrm{mm}$ sieves. The three classes of interest in the subsequent thermochemical conversion were used for the bulk and tapped density determinations.

Feedstock will inevitably be handled in the form it is received before being ground into a final size, depending on the optimum feed particle size stipulated for the conversion equipment and process. For instance, some studies specify a size range of between 1.5-3 $\mathrm{mm}$ for fluidized bed pyrolysis or gasification, while larger sizes are acceptable for fixed bed pyrolysis or combustion [25]. In the case where the conversion plant is distant from the storage and pretreatment sites, it would, therefore, be good to know whether to grind the biomass to the size required by the conversion process at the beginning or to handle it in its received state until just before the conversion process.

A digital mass balance was used to weigh a container of known volume $(0.280 \mathrm{~L})$, then tared, subsequently. Biomass samples from each size class were then poured into the container from a constant height and leveled off. The actual mass of the biomass on balance was recorded. The bulk density, $D_{b}$, was calculated as follows:

$$
D_{b}=\frac{\sum M_{p}}{V_{c}}
$$

where $\sum M_{p}$ is the total particle mass, and $V_{c}$ is the volume of the container. Tapped density $D_{t}$ was determined by tapping the poured sample 30 times, adding more biomass, then tapping 20 times again. The samples were leveled off, and the mass of the compressed biomass was measured. Tapped density $D_{t}$ was then calculated as follows:

$$
D_{t}=\frac{\sum M_{t p}}{V_{c}}
$$

where $\sum M_{t p}$ is the total mass of the tapped particles. Four sets of experiments were done to obtain a more accurate averaged result, and an error analysis was conducted.

\subsubsection{Flowability and Compressibility: The Hausner Ratio and Carr Index}

The Hausner ratio and Carr index are derived properties calculated from the bulk and tapped densities, indicating the flowability and compressibility of the biomass. The higher the Hausner or Carr indices, the more compressible the biomass [11]. The Hausner and Carr indices were calculated as follows, using the already defined parameters $D_{t}$ and $D_{b}$ :

$$
\begin{gathered}
\text { Hausner }=\frac{D_{t}}{D_{b}} \\
\text { Carr }=\frac{100\left(D_{t}-D_{b}\right)}{D_{b}}
\end{gathered}
$$

\section{Results and Analysis}

This section catalogues the results obtained from the tests in Section 2. It is mainly divided into two subsections to cover "Compositional and thermal properties" and "Physical properties". 
The analyses and discussion of the results were done as they are presented, and then a summary discussion is also supplied in Section 4.

\subsection{Compositional and Thermal Properties}

\subsubsection{Calorimetry, Thermogravimetry, Ultimate and Proximate Analyses}

Figure 2 shows a typical TGA profile for a pine sample. The proximate composition was determined from the plateau regions and is shown in Table 2.

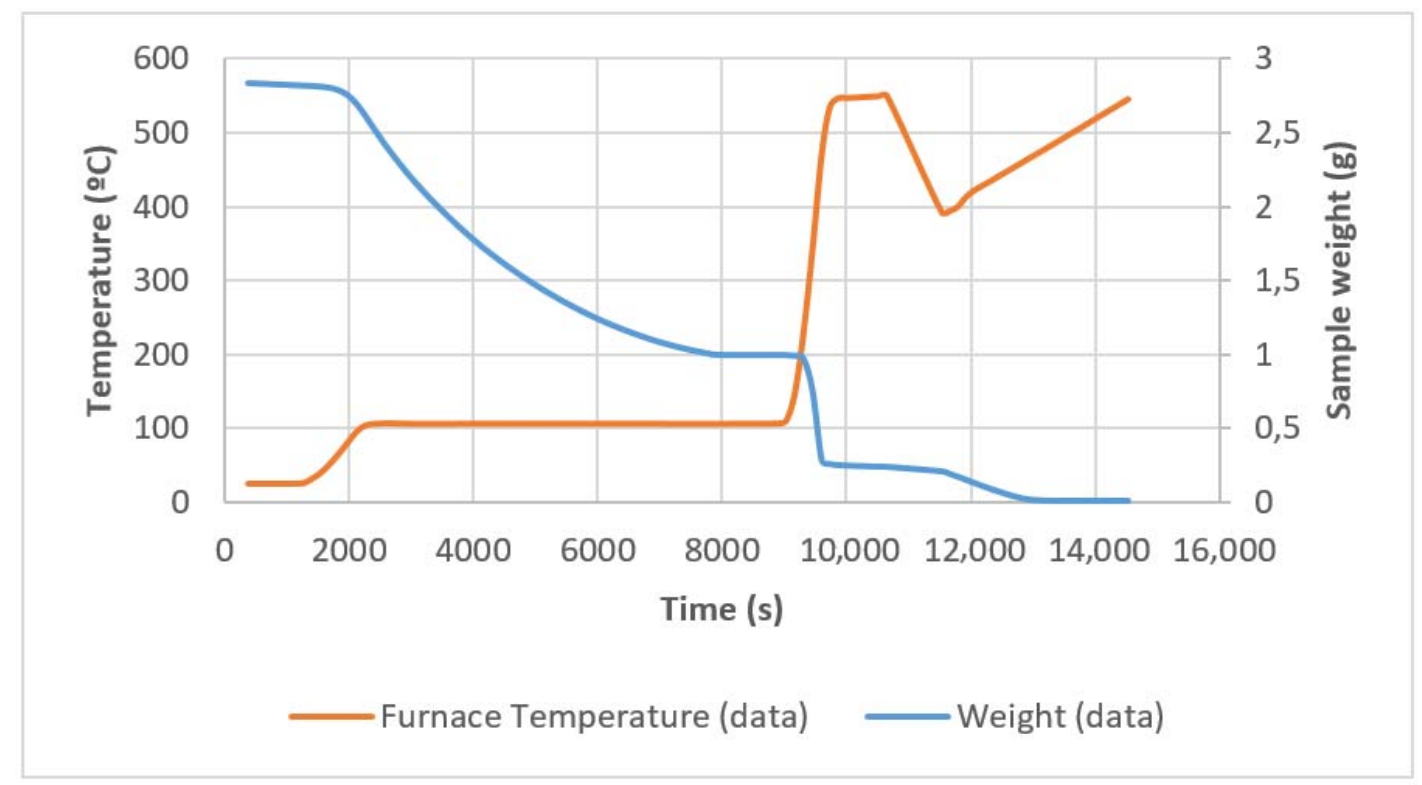

Figure 2. Thermogravimetric analyzer (TGA) weight loss curves for pine dust for a sample of $2.80 \mathrm{~g}$.

Figure 2 shows the thermal degradation profile for weight loss against time and temperature rise against time for the sample. As can be seen from the profile, the initial weight loss began after $33 \mathrm{~min}$ from the beginning and continued for just over an hour until the $2.80 \mathrm{~g}$ sample reduced to $1 \mathrm{~g}$. This long drying duration shows that the pine dust samples had high moisture contents. When the temperature was ramped up to $550^{\circ} \mathrm{C}$, still within the inert environment, another weight-loss profile occurred for $30 \mathrm{~min}$, until the TGA automatically stopped after registering a constant mass. The lids were then taken off to allow free air circulation during the ashing process in an oxygen environment. The exposure to a cool atmosphere explains the sudden drop in temperature from $550^{\circ} \mathrm{C}$ to $400{ }^{\circ} \mathrm{C}$. After removing the caps, the temperature was ramped back to $550{ }^{\circ} \mathrm{C}$. The ashing immediately commenced when the temperature had just reached the set point and continued until the sample reached a constant weight; then, the TGA automatically stopped.

Figure 3 shows the TGA weight-loss curves for the debarked acacia and that with bark.

The profiles for the various forms of acacia ("debarked" and "with bark") were mostly the same, with slight variations in the final proximate compositions. Figure 3 shows that there is little loss of weight on the acacia-drying profile duel to the low MC of $3.72 \%$ compared to $65.41 \%$ for the pine sawdust on an "as-received" basis. No air-drying had yet been done, and the pine dust was coming from humid storage conditions. When the two biomasses' weight-loss profiles were compared, it was noted that the drying step takes slightly less than $30 \mathrm{~min}$ for the acacia, while it takes $100 \mathrm{~min}$ for the pine. The volatization and ashing steps take 17 and $50 \mathrm{~min}$, respectively. The volatization step is longer for pine dust (30 $\mathrm{min})$, attesting to the higher $\mathrm{VC}$, while the ashing period is almost the same. 


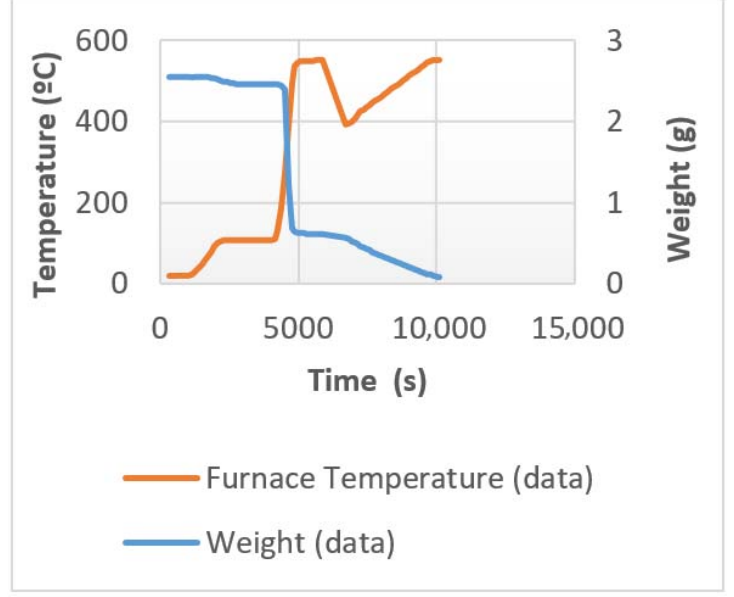

(a)

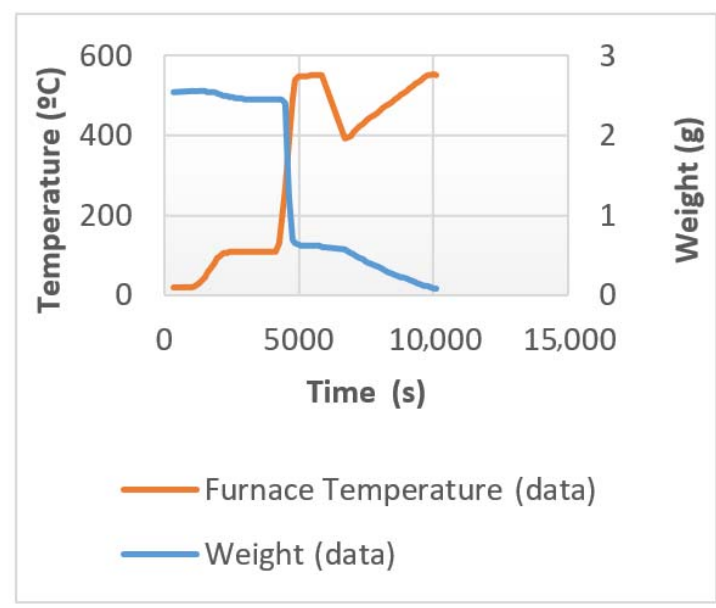

(b)

Figure 3. TGA weight-loss curves for (a) debarked acacia and (b) acacia with bark.

It was further observed that there were random differences in the proximate composition between debarked samples and those that had bark, with no particular trend. The thinness of the acacia shrub bark layer could make its contribution to the results insignificant. Other authors such as Olatunji et al. [26], however, observed higher ash contents and a lower HHV for samples with bark (from mature trees) compared to the debarked biomass. As a consequence of our findings, only the proximate compositions for the samples with bark were adopted, since it is also quite unlikely that the Acacia tortilis will be debarked before conversion or valorization exercises. The calorimetry, thermogravimetry proximate and ultimate analyses results are summarized in Table 3.

Table 3. Results of ultimate and proximate analyses (dry basis) for acacia, compared to the common pine. FC—fixed carbon, VM-volatile matter and MC—-moisture content.

\begin{tabular}{cccccccccc}
\hline \multirow{2}{*}{$\begin{array}{c}\text { Lignocellulosic } \\
\text { Biomass }\end{array}$} & \multicolumn{3}{c}{ Ultimate Analysis (\%)-An Average of $\mathbf{c}$} & \multicolumn{5}{c}{ Proximate Analysis (\%) (Dry Basis)—Averages } & HHV (MJ/kg) \\
\cline { 2 - 9 } & $\mathbf{C}$ & $\mathbf{H}$ & $\mathbf{N}$ & $\mathbf{O}^{\mathbf{1}}$ & Ash & FC & VM & MC \\
\hline ACACIA & 41.47 & 5.15 & 1.23 & 52.15 & 3.90 & 19.59 & 76.51 & 3.72 \\
PINE DUST & 45.76 & 5.54 & 0.039 & 48.66 & 0.83 & 20.00 & 79.16 & $65.41^{2} / 6.50^{3}$ & 17.267 \\
\hline
\end{tabular}

${ }^{1}$ Oxygen calculated by difference, considering that $S=0 .{ }^{2}$ Moisture content as received. ${ }^{3}$ Moisture content after solar-drying for at least 3 weeks.

Table 3 shows that the HHV for Acacia tortilis is not very different from that of pine dust, though the acacia has a considerably higher ash content and a slightly lower fixed carbon. The higher fixed carbon of the pine dust explains why it would have a higher HHV compared to acacia. The FC of Acacia tortilis corresponds with the low C content in the ultimate analysis (41\%), which is also smaller in comparison to the $44 \%$ in Acacia Holosericea [17]. The higher VM in the pine dust also indicates it may have a more favorable conversion efficiency, with potential for a higher yield of bio-oil in pyrolysis, for instance. On the other hand, the higher ash content $(3.90 \%)$ in A. tortilis shows there is a higher mineral content, making it more prone to fouling and slagging compared to the pine; however, the figure is below the critical $6 \%$ stipulated for gasification systems [13]. This figure is comparable to Acacia Holosericea with an ash content of $3.91 \%$. It would be interesting to investigate if the mineral content in the acacias would not have a significant impact on the yield and quality of bio-oil obtained through pyrolysis. The pine residues also have more VM (79.16\%) than Acacia tortilis (76.51\%). However, the latter's VM is higher than other acacia species studied: Acacia holosericea $(65.32 \%)$, Acacia mangium $(65.2 \%)$ and Acacia auriculiformis (65.37\%). Overall, it does seem that pine dust would be a better feedstock for thermochemical conversions compared to acacia, although this would further depend on the particular conversion and the targeted products. 
The ultimate analysis results corroborate with the proximate study, which shows a higher FC content in the pine residues compared to acacia. There was no $S$ detected for both biomass types, though acacia registered a significant $\mathrm{N}$ content $(1.23 \%)$ due to its nitrogen-fixing and retaining capabilities. This $\mathrm{N}$ content is considerably higher compared to $0.25 \%$ in Acacia Holosericea, and in both acacias, $\mathrm{S}$ was not detected. Charis et al. [10] noted that the pine dust from Zimbabwe has relatively lower $\mathrm{N}$ and S contents compared to the Canadian (N: $0.14 \%$ and S: $0.01 \%$ ) and Spanish $(\mathrm{N}: 0.16 \%-1.6 \%$ and S: $0.14 \%-0.45 \%)$, making it a cleaner thermochemical feedstock $[5,7]$. In general, the low amounts of $\mathrm{N}$ and $\mathrm{S}$ in the pine dust and acacia imply that the two biomass types have a lower environmental burden compared to fossil fuels. A further comparison of the ultimate, proximate and calorimetric analyses of the sawdust with other pine residues from the literature was made. The HHV for pine sawdust (17.568 MJ/kg) was higher than the value of $15.01 \mathrm{MJ} / \mathrm{kg}$ quoted by Braza and Crnkovic [4] but lower than that found by Olatunji et al. [26] of $20.54 \mathrm{MJ} / \mathrm{kg}$. The range is, however, acceptable, and the differences could be due to varying MCs. The pine dust in this study has the lowest $C$ content at $45.76 \%$ compared to $48.62 \%$ by Braza and Crnkovic [ 4 ] and $50.54 \%$ by Olatunji et al. [26], as well as the highest O content at $48.66 \%$ compared to $43.20 \%$ and $41.11 \%$ from the two other studies, respectively. Most proximate parameters were found to have values somewhere between those obtained by Braza and Crnkovic [4] and Olatunji et al. [26] except for the MC and fixed carbon, which were the highest for the pine dust in this study. The differences in compositional values for the pine sawdust show how variations can occur due to various storage and environmental factors or as a result of the different soil and climatic conditions in which the trees were nurtured.

\subsubsection{FTIR Analysis}

Figures 4 and 5 show the peaks obtained from the FTIR scan of the Acacia tortilis and pine dust samples, respectively. The functional groups most possibly represented by the peaks were determined by referring to the literature, as shown in Table 4.

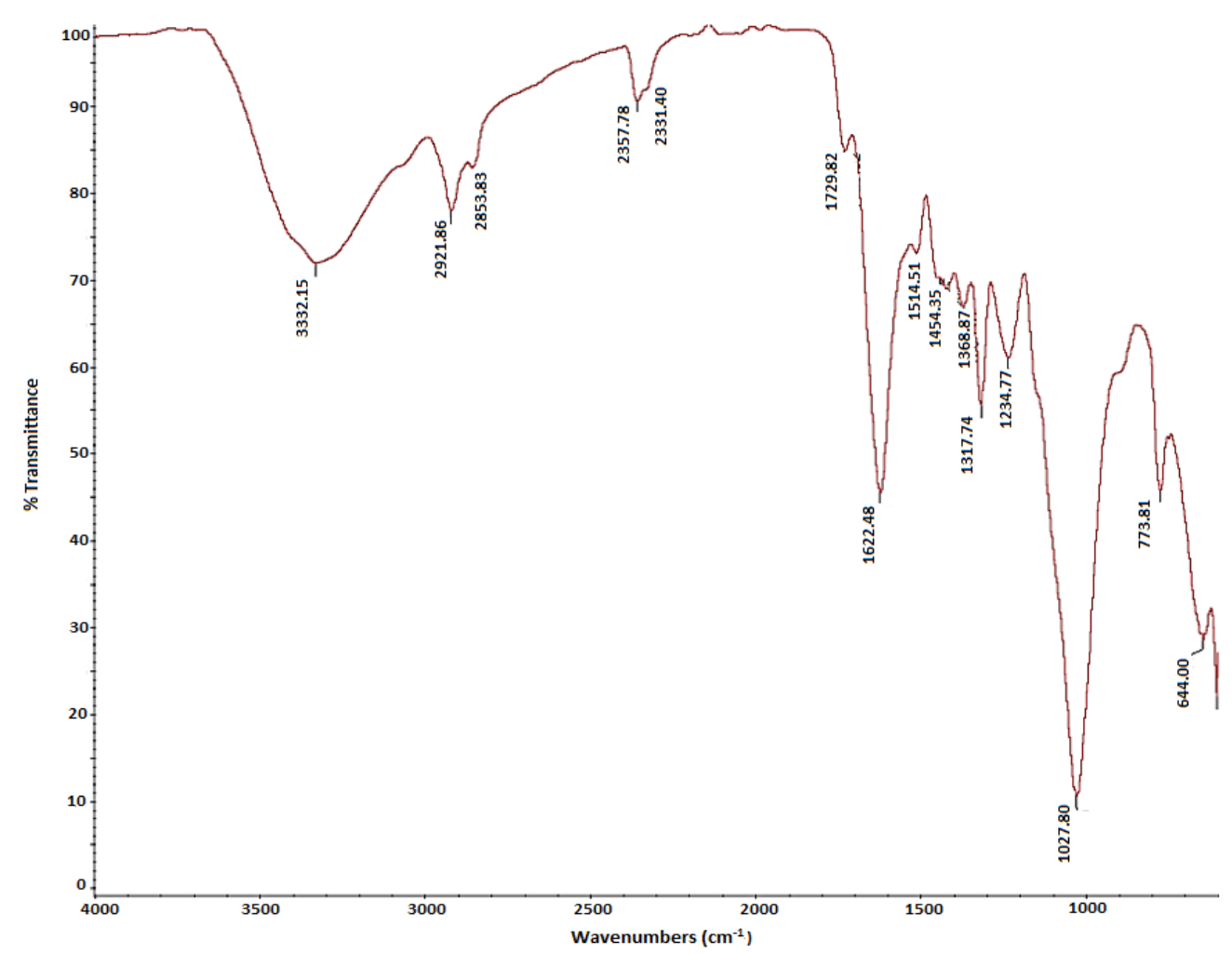

Figure 4. Fourier-transform infrared spectroscopy (FTIR) peaks for Acacia tortilis. 


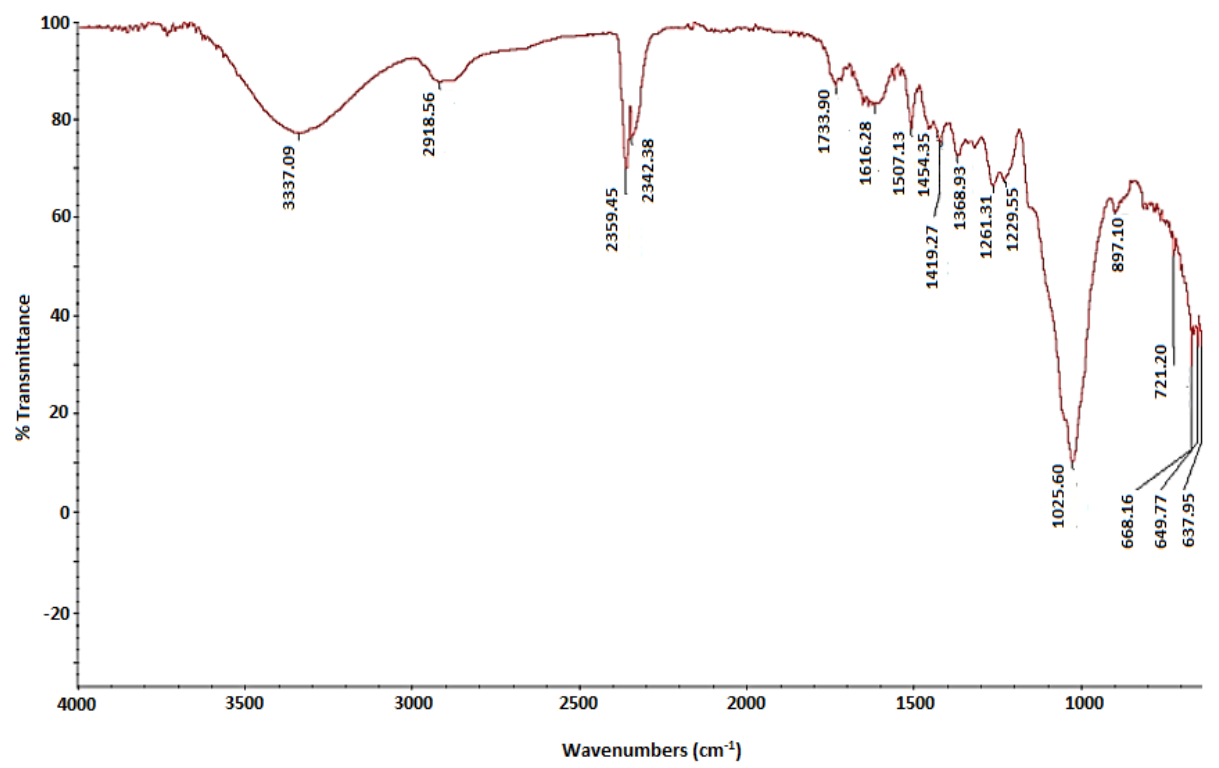

Figure 5. FTIR peaks for pine dust.

Table 4. Compounds represented by the acacia and pine FTIR peaks.

\begin{tabular}{|c|c|c|c|c|}
\hline $\begin{array}{l}\text { Absorption } \\
\text { Peak-Acacia }\end{array}$ & Absorption Peak-Pine & $\begin{array}{l}\text { Possible Compounds/Chains } \\
\text { Rationale }\end{array}$ & $\begin{array}{l}\text { Type of Vibration Causing } \\
\text { the IR Absorption }\end{array}$ & Literature \\
\hline 3332.15 & 3337.09 & $\begin{array}{l}\text { Phenols, carboxylic acids and } \\
\text { alcohols (broader peak) }\end{array}$ & $\begin{array}{l}\text { Hydrogen-bonded } \mathrm{OH} \\
\text { stretch in cellulose } \\
\text { and lignin }\end{array}$ & {$[17,27]$} \\
\hline 2921.86 & 2918.56 & $\begin{array}{l}\text { Alkanes or primary amine } \\
\text { Alkanes and acids }\end{array}$ & $\begin{array}{l}\mathrm{H}-\mathrm{C}-\mathrm{H} \text { asymmetric and } \\
\text { symmetric stretch }\end{array}$ & {$[17,27]$} \\
\hline \multirow[t]{2}{*}{2853.83} & & Alkanes or aldehydes & $\begin{array}{l}\mathrm{H}-\mathrm{C}-\mathrm{H} \text { asymmetric and } \\
\text { symmetric stretch; } \\
\mathrm{C}-\mathrm{H} \text { branch off } \mathrm{C}=\mathrm{O}\end{array}$ & {$[17,27]$} \\
\hline & 2359.45 & Alkanes and acids & $\begin{array}{l}\mathrm{H}-\mathrm{C}-\mathrm{H} \text { asymmetric and } \\
\text { symmetric stretch; } \\
\mathrm{C}-\mathrm{H} \text { branch off } \mathrm{C}=\mathrm{O}\end{array}$ & {$[28,29]$} \\
\hline 2357.78 and 2331.40 & 2342.38 & Carbon dioxide & $\mathrm{CO}_{2}$ & {$[28,29]$} \\
\hline 1729.82 & 1733.90 & $\begin{array}{l}\text { Ketones and aldehydes } \\
\text { Carboxylic acid }\end{array}$ & $\mathrm{C}=\mathrm{O}$ stretch in hemicellulose & {$[17,27]$} \\
\hline 1622.48 & 1616.28 & Alkenes & $\mathrm{sp}^{2} \mathrm{C}-\mathrm{X}$ double bond & {$[28,29]$} \\
\hline 1514.51 & 1507.13 & Secondary Amine confirmed & $\mathrm{N}-\mathrm{H}$ bend & {$[28,29]$} \\
\hline 1454.35 & 1454.35 & Alkanes confirmed & $\mathrm{H}-\mathrm{C}-\mathrm{H}$ bend & {$[28,29]$} \\
\hline \multirow[t]{2}{*}{1422.69 (actual: 1425$)$} & & Lignin and wood & $\mathrm{CH}$ in-plane deformation & [17] \\
\hline & 1419.27 & Alkanes & $\mathrm{sp}^{3} \mathrm{C}-\mathrm{H}$ bend & {$[28,29]$} \\
\hline 1368.87 and 1317.74 & 1368.93 & & $\begin{array}{l}\text { C-H deformation in } \\
\text { cellulose and hemicellulose }\end{array}$ & [17] \\
\hline \multirow[t]{2}{*}{1234.77 and 1027.80} & $\begin{array}{l}1261.31,1229.55 \\
\text { and } 1025.60\end{array}$ & Esters or ethers & $\begin{array}{l}\text { Alkoxy C-O stretch and C-O } \\
\text { stretch in cellulose, } \\
\text { hemicellulose or lignin }\end{array}$ & {$[28,29]$} \\
\hline & 897.10 and 721.20 & $\begin{array}{l}\text { Aromatic rings and meta } \\
\text { di-substituted compounds }\end{array}$ & $\mathrm{sp}^{2} \mathrm{C}-\mathrm{H}$-bending patterns & {$[28,29]$} \\
\hline $773.81,644.00$ and 604.05 & 668.16 to 604.56 & $\begin{array}{l}\text { Fingerprint regions not easy to } \\
\text { unknown compound }\end{array}$ & nterpret for a previously & [17] \\
\hline
\end{tabular}

The FTIR image for the pine dust in Figure 5 seems to have more functional groups (16) depicted by the peaks below the 2200- $\mathrm{cm}^{-1}$ wavenumber, compared to 12 groups for the acacia in Figure 4 .

Table 4 shows the interpretation of the peaks obtained in the FTIR for the two biomasses. The functional groups at those peaks were identified by comparing with the standards derived from the literature.

Using the FTIR analyses, we identified many functional groups in both biomass samples, attesting to the heterogeneous nature of the biomasses. The FTIR analyses indicated the presence of a wide range of compounds within the cellulose, hemicellulose and lignin structures [30]. Reza et al. [17] explicitly linked the C-H bond stretch in the region $2960-2850 \mathrm{~cm}^{-1}$ to the presence of lignin, hemicellulose and 
cellulose in the biomasses. They further associated the area between 2000 and $1650 \mathrm{~cm}^{-1}$ to the $\mathrm{C}-\mathrm{H}$ bonding in cellulose and hemicellulose, while the region $1750-1630 \mathrm{~cm}^{-1}$ was mainly linked with the $\mathrm{C}=\mathrm{O}$ in hemicellulose. This finding is in tandem with literary works like Ahmed et al. [27] and Naik et al. [7]. The functional groups identified in pine dust are mostly the same as those in Acacia tortilis, though in varying quantities. The peak at wave $2853.83-\mathrm{cm}^{-1}$ frequency seemed to suggest a more substantial presence of aldehydes or alkanes in the acacia, while the one at $1422.69 \mathrm{~cm}^{-1}$ suggested a stronger lignin presence in this hardwood, as expected and compared to the pine softwood. Pine dust also had prominent peaks at $2359.45 \mathrm{~cm}^{-1}$ and $1419.27 \mathrm{~cm}^{-1}$, which suggested a strong presence of alkanes as well. Further analyses would be required to tell the exact comparative alkane compositions. The other peaks at $897.10 \mathrm{~cm}^{-1}$ and $721.20 \mathrm{~cm}^{-1}$ for the pine dust suggested a significant presence of aromatic rings, meta di-substituted compounds. The analyses of pyrolysis products in the latter stages of the bioenergy project using FTIR and other scanning calorimetry methods could help to confirm these results and simulate the possible conversion pathways. The other difference in the FTIR results for the two biomasses was the presence of a broader fingerprint region (six clumped peaks) of unknown functional groups for the pine dust, in the range $604.56-668.16 \mathrm{~cm}^{-1}$. Meanwhile, the Acacia tortilis' lower-end fingerprint region only comprised three unknown peaks at $603.05,644$ and $773.81 \mathrm{~cm}^{-1}$. For both lignocellulosics, the FTIR analyses showed more functional groups than those reported by Reza et al. [17] and Ahmed et al. [27]. The acacia's FTIR results agree with the studies on other acacias published by Reza et al. [17] and Ahmed et al. [27], especially at the peaks depicted by wavenumbers $3332.15 \mathrm{~cm}^{-1}, 2921.86 \mathrm{~cm}^{-1}, 2853.83 \mathrm{~cm}^{-1}, 1729.82 \mathrm{~cm}^{-1}$ and $1422.69 \mathrm{~cm}^{-1}$ and the corresponding functional groups.

\subsection{Physical Properties}

The MC has already been covered under the compositional analysis. The results for the other physical properties, mainly the particle, bulk and tapped densities are presented in this section. Using these values, the Hausner and Carr indices, which indicate the compressibility and flowability of the biomasses, were calculated.

\subsubsection{Particle Density}

The average density from three particles, as calculated by Equation (1) from Section 2.2.1, was $478.8 \mathrm{~kg} / \mathrm{m}^{3}$ for pine and $867.3 \mathrm{~kg} / \mathrm{m}^{3}$ for the Acacia tortilis particles. The average density obtained for the pine dust was close to the $490 \mathrm{~kg} / \mathrm{m}^{3}$ stipulated by the pinus patula datasheet [31]. Logically, pine residues that have been under various storage conditions and exposed to different weather elements would differ in some physical properties from freshly harvested pine trees. Furthermore, the density of the Acacia tortilis $\left(867.3 \mathrm{~kg} / \mathrm{m}^{3}\right)$ was almost double that of the pine $\left(478.8 \mathrm{~kg} / \mathrm{m}^{3}\right)$, as expected for a hardwood compared to the pine softwood.

\subsubsection{Bulk and Tapped Density}

Figure 6 shows the mean values obtained from four runs on bulk density and tapped density for both biomasses and the relative standard error associated with the type of biomass. These mean values were then used to calculate the Hausner ratios and Carr's indices for various size ranges. 


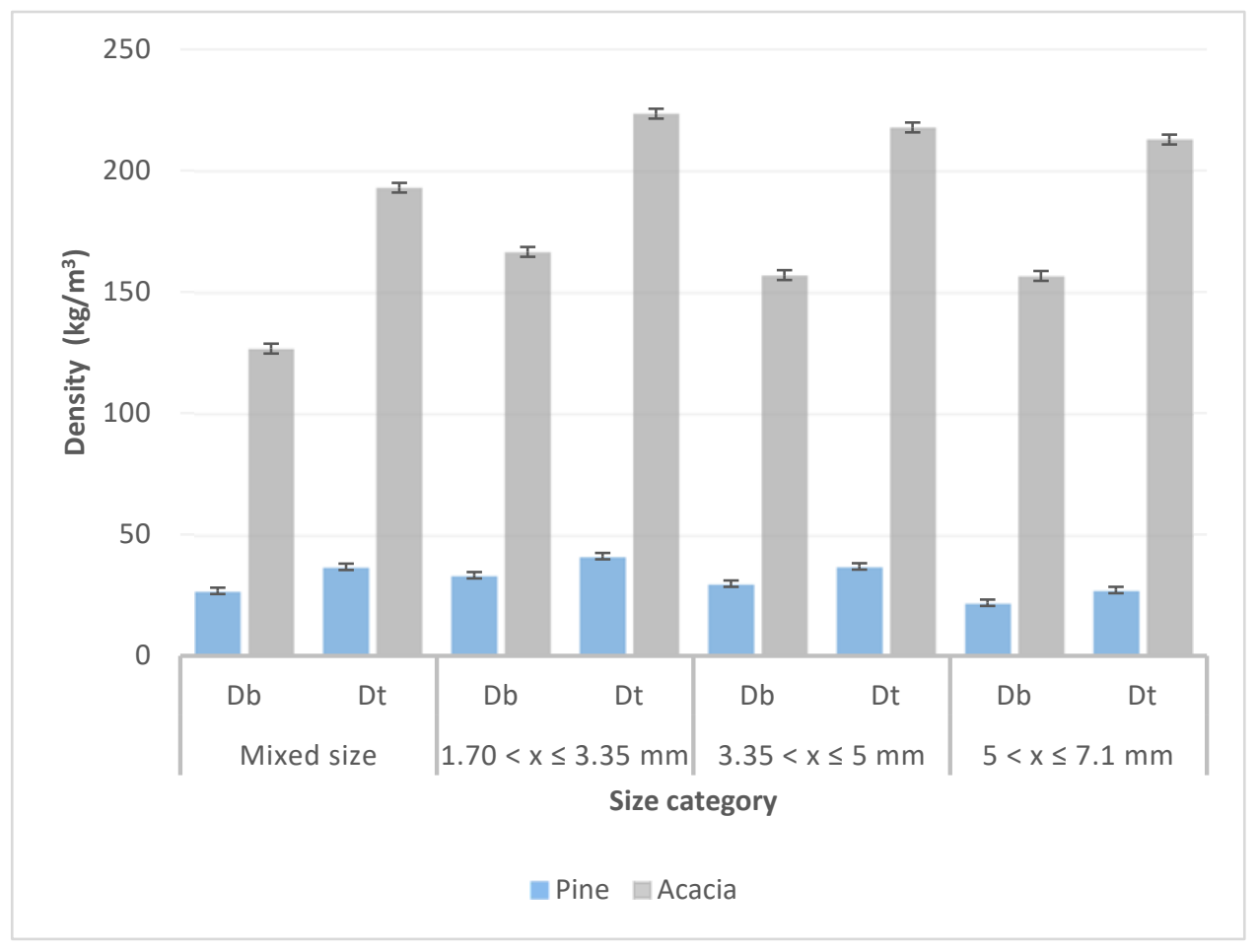

Figure 6. Bulk and tapped densities for various size classes of pine and acacia samples. Db: bulk densities and Dt: trapped densities.

The bulk and tapped densities of the acacia were at least four times larger than for pine, because they are a function of the number of particles contained in the fixed volume and the mass of each particle, according to Equation (2) in Section 2.2.2. These densities are an essential consideration when the biomass is being transported or stored for subsequent thermochemical conversion. In this case, the energy stored or transported per unit volume would be a lot larger for the Acacia tortilis compared to the pine dust. For example, in the size range $3.35 \mathrm{~mm}<\mathrm{x} \leq 5 \mathrm{~mm}$, one cubic metre of pine dust stored or transported would have equivalent energy of 522.1 MJ compared to $2709.7 \mathrm{MJ}$ for the same size range for acacia. The formula for calculating the bulk energy density $\left(E D_{b}\right)$ of the biomass is given by Equation (6):

$$
E D_{b}=D_{b} \times H H V
$$

\subsubsection{The Hausner Ratio and Carr index}

Figures 7 and 8 show the Hausner ratios and Carr calculated from the mean values of the bulk and tapped densities from Figure 6. The calculations were made according to Equations 4 and 5 provided in Section 2.2.2.

For both samples, the mixed size (as-received basis) had the highest Hausner ratio and Carr's index, indicating higher compressibility. This result is probably because, during tapping, the smaller particles fill in the voids left by the bigger particles. Consequently, it may be desirable to store and transport mixed size fractions (mostly as-received) within a specific range to make optimal use of the space. The acacia biomass also has higher Hausner's ratios and Carr indices than pine, which shows it is a more compressible biomass type. 


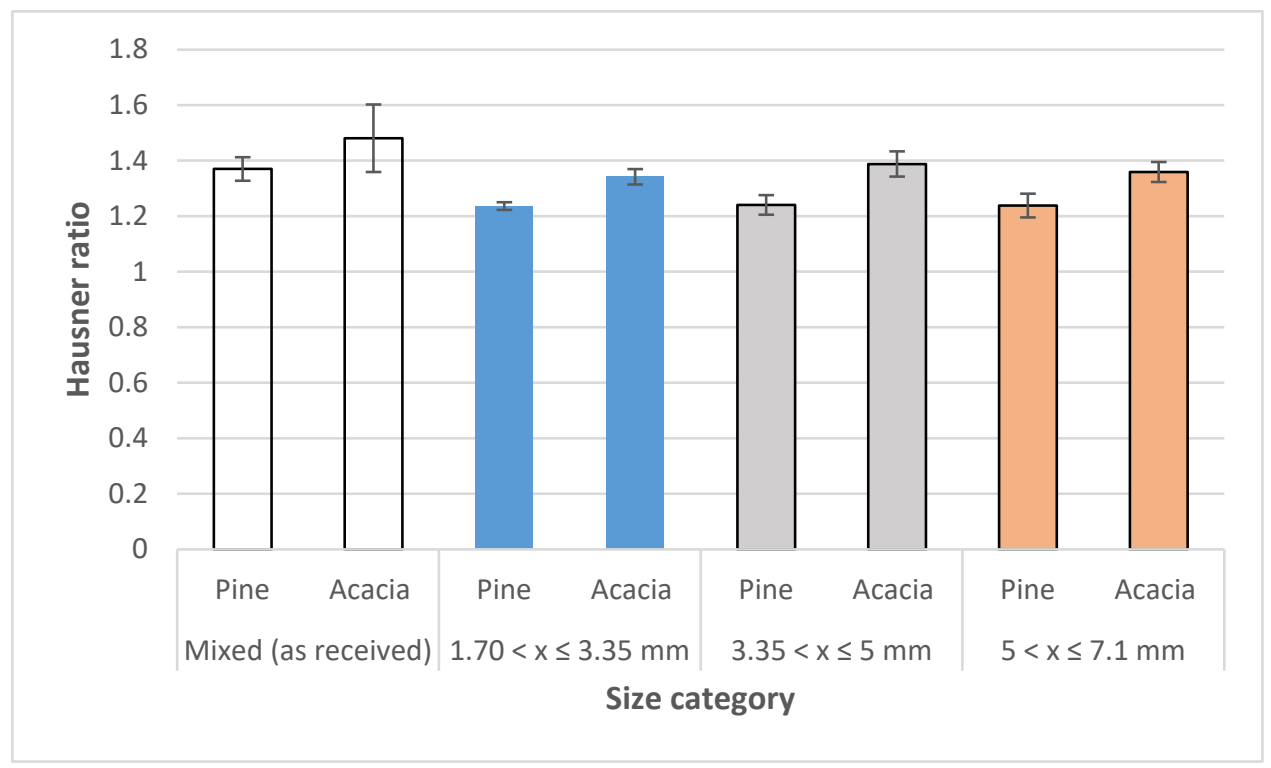

Figure 7. Hausner ratios for pine and acacia.

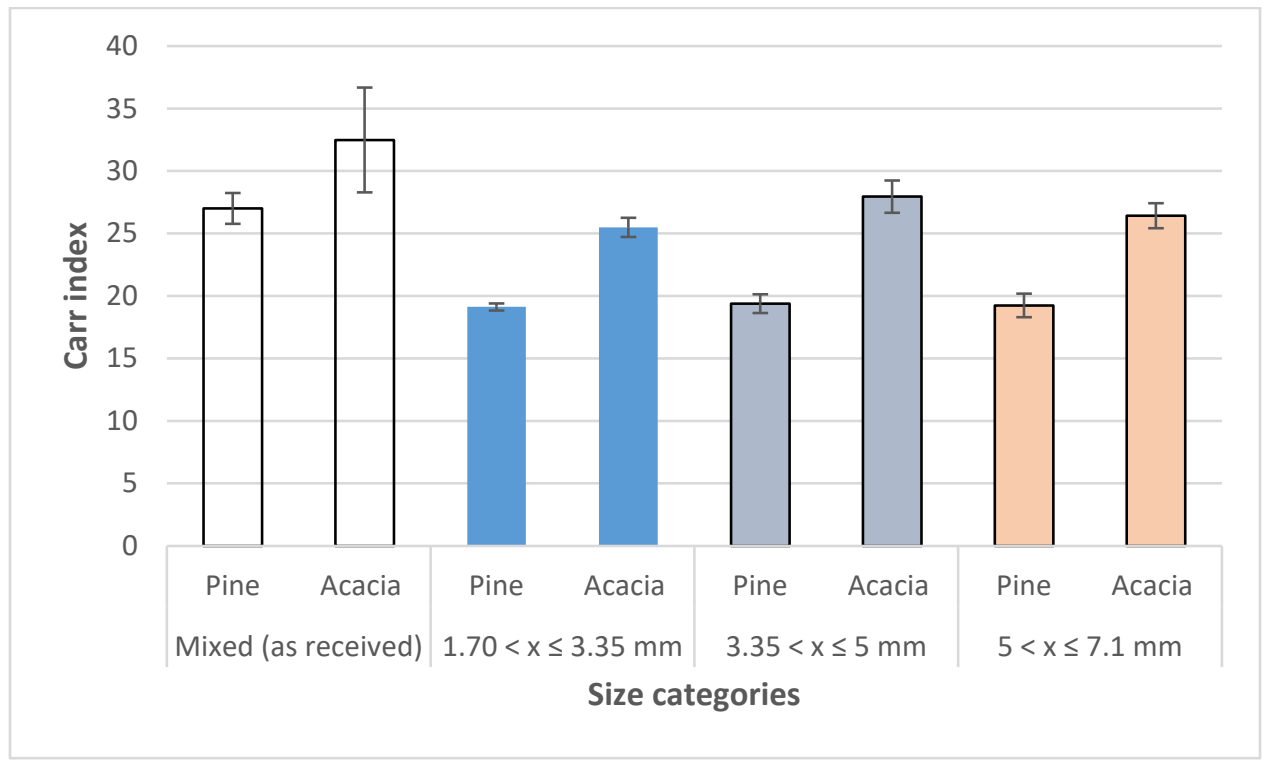

Figure 8. Carr indices for pine and acacia.

\section{Discussion}

The characterization of the two biomass feedstocks makes it possible to predict their behaviors at various steps of the supply chain and add any necessary pretreatments. Table 5 discusses the results obtained from the previous section with regards to their implications on supply-chain (SC) dynamics like transport, handling, storage, conversion and the overall economics, as hinted in Table 1. 
Table 5. The implications of the characterization results on the supply-chain (SC) dynamics, economics and the environment.

\begin{tabular}{|c|c|c|c|}
\hline \multicolumn{2}{|c|}{ Physicochemical Properties } & $\begin{array}{l}\text { Comparative Status of the Properties for Acacia } \\
\text { and Pine Dust }\end{array}$ & $\begin{array}{l}\text { Potential Effects on SC Dynamics, Economics } \\
\text { and Environment }\end{array}$ \\
\hline \multicolumn{2}{|c|}{ Elemental composition (CHNS-O) } & $\begin{array}{l}\text { Higher } \mathrm{N} \text { content in } A \text {. tortilis compared to pine dust. } \\
\text { Both biomasses have no } \mathrm{S} \text { detected. } \\
\text { Higher } \mathrm{O} / \mathrm{C} \text { ratio in } A \text {. tortilis }(1.25) \text { compared to pine } \\
\text { dust (1.06). }\end{array}$ & $\begin{array}{l}\text { Both biomasses have low } \mathrm{N} \text { and } \mathrm{S} \text { contents, implying a } \\
\text { lower environmental impact compared to fossils [13]. } \\
\text { Costs of scrubbing are circumvented. } \\
\text { Higher O/C ratio would affect the quality of some } \\
\text { products or by-products, such as pyrolysis oil, though } \\
\text { marginally compared to the pine dust [32]. }\end{array}$ \\
\hline \multirow{4}{*}{$\begin{array}{l}\text { Proximate } \\
\text { composition }\end{array}$} & Moisture content & $\begin{array}{l}\text { The MC of pine dust }(65.41 \%) \text { on an "as-received" } \\
\text { basis is way higher than for acacia }(3.72 \%) \text {. } \\
\text { Solar-dried pine goes down to } 6.50 \% \text {. }\end{array}$ & $\begin{array}{l}\text { Solar-drying can be used to bring pine dust MC down, } \\
\text { but that exposes it to contamination with dust, etc., } \\
\text { which affects the quality of conversion products. Other } \\
\text { methods of drying would mean extra costs. High MC } \\
\text { lowers the HHV of a biomass [33]. }\end{array}$ \\
\hline & Ash content & $\begin{array}{l}\text { Higher ash content in acacia }(3.90 \%) \text { compared to } \\
\text { pine dust }(0.83 \%) \text {. }\end{array}$ & $\begin{array}{l}\text { The ash in acacia is below the critical fouling and } \\
\text { slagging level (6\%). It could, however, act as a catalyst in } \\
\text { processes like pyrolysis, decreasing the yield and quality } \\
\text { of bio-oil [34]. This would, however, need to be } \\
\text { confirmed with the actual pyrolysis set-up. }\end{array}$ \\
\hline & Volatile matter & $\begin{array}{l}\text { Higher VM in pine dust }(79.16 \%) \text { compared to } \\
\text { acacia }(76.51 \%) \text {. }\end{array}$ & $\begin{array}{l}\text { There could be higher yields/recoveries of liquid or } \\
\text { gaseous products from conversions like pyrolysis and } \\
\text { gasification [9]. It does not, however, indicate the quality } \\
\text { of the gas or liquid product. }\end{array}$ \\
\hline & Fixed carbon & $\begin{array}{l}\text { A slightly lower FC in acacia }(19.59 \%) \text { compared to } \\
\text { pine dust }(20.00 \%) \text {. }\end{array}$ & $\begin{array}{l}\text { The difference is not significant, though it could explain } \\
\text { why the acacia has a slightly lower HHV compared to } \\
\text { pine dust. }\end{array}$ \\
\hline \multicolumn{2}{|l|}{ HHV } & $\begin{array}{l}\text { A slightly lower HHV in acacia }(17.267 \mathrm{MJ} / \mathrm{kg}) \\
\text { compared to pine dust }(17.568 \mathrm{MJ} / \mathrm{kg}) \text {. }\end{array}$ & $\begin{array}{l}\text { The moderately high HHV means both can be exploited } \\
\text { well by thermochemical means, including upgrading } \\
\text { their energy value through torrefaction [14]. The latter } \\
\text { would bring their energy value closer to that of coal. }\end{array}$ \\
\hline \multicolumn{2}{|c|}{ Densities and compressibility } & $\begin{array}{l}\text { The particle, bulk and tapped densities of acacia are } \\
\text { about } 2-4 \text { times higher than for pine dust. }\end{array}$ & $\begin{array}{l}\text { This fact brings an advantage for acacia in terms of } \\
\text { storage and energy density. For the size range } 3.35 \mathrm{~mm}< \\
x \leq 5 \mathrm{~mm} \text {, acacia has an energy density of } 2709.7 \mathrm{MJ} / \mathrm{m}^{3} \\
\text { compared to } 522.1 \mathrm{MJ} / \mathrm{m}^{3} \text { for pine dust. More energy } \\
\text { values can be recovered for the same volume of stored, } \\
\text { transported or fed acacia (Section } 3.2 .2 \text { ). Figures } 7 \text { and } 8 \\
\text { show that the acacia generally has a higher } \\
\text { compressibility, and, coupled with the energy density } \\
\text { factor, it has a better potential for compressed wood } \\
\text { products [18]. }\end{array}$ \\
\hline \multicolumn{2}{|c|}{ Functional groups } & Multiple functional groups for both biomass types. & $\begin{array}{l}\text { This result proves there are many compounds in the } \\
\text { biomasses, which is also characteristic of some of the } \\
\text { conversion products like bio-oil [34]. Consequently, } \\
\text { separation and purification to derive chemicals or fuels } \\
\text { from the oil becomes a costly and challenging task. }\end{array}$ \\
\hline
\end{tabular}

\section{Conclusions and Recommendations}

Various literature sources have confirmed the importance of the physicochemical characterizations of biomasses, a primary step in exploring the feasibility of exploiting them for bioenergy. For this particular study, the characterization results concurred with general expectations emanating from the tree classifications. They also compared well with studies of similar biomasses from the literature. The comparative study showed that pine dust has better fuel properties per unit weight than Acacia tortilis due to its higher HHV and fixed carbon, with low ash and oxygen contents. However, since Acacia tortilis' thermochemical properties are not very far from those of pine, and the ash content $(3.61 \%)$ is about half the critical slagging and fouling value of $6 \%$, it can also be effectively exploited thermochemically [13]. Moreover, the energy density (energy per unit volume) of Acacia tortilis is about four times larger than for the pine dust due to its higher bulk density, giving it an advantage in storage and the actual thermochemical conversions. The considerably higher particle, bulk and tapped densities for Acacia tortilis compared to pine are expected, since the former is a hard wood, while the latter is a soft wood. Such high bulk-energy densities of Acacia tortilis also mean that it can be compressed into pellets or briquettes of higher energy values compared to pine dust. Since both biomasses are wastes in their local contexts, and their thermochemical properties are within the recommended ranges, they can be converted by any of the combustion, gasification and pyrolysis routes. They can also be torrefied or carbonized into charcoal to obtain solid fuels of higher heating values. Further experiments can be carried out for the various conversion routes to determine the 
optimal conditions and the properties of the products. For storage purposes, it seems more convenient to store the feedstocks as they are received, or after the first grind, while they have a mixed size range that is more compressible than uniform sizes.

There were also some limitations in the study, mainly in the FTIR analysis and particle density measurements. It is ideal to have a library of standards attached to the FTIR spectrometer to identify the functional groups directly; however, the equipment used did not have such a library. Therefore, the literature was used to make inferences, using findings done before by other authors. A pycnometer is recommended for densities of small particles; however, since it was not available, particle dimensions were used as the next most-appropriate method.

Although feedstock characterizations give a broad picture of the expected behavior of a material in subsequent stages, further tests still need to be done to confirm such predictions and derive specific results for the actual logistic and conversion stages.

Author Contributions: Conceptualization, data curation and writing-original draft preparation, G.C.; writing-review and editing, G.D. and E.M. and supervision, G.D. and E.M. All authors have read and agreed to the published version of the manuscript.

Funding: This research received no external funding.

Acknowledgments: We acknowledge the support of the Botswana International University of Science and Technology and the University of Johannesburg.

Conflicts of Interest: The authors declare no conflicts of interest.

\section{Abbreviations and Symbols}

$\begin{array}{ll}\text { Abbreviation } & \text { Explanation } \\ \text { ASTM } & \text { American Society for Testing and Materials } \\ \text { CHNS-O } & \text { Carbon, hydrogen, nitrogen and sulphur; oxygen determined by the difference } \\ D_{b} & \text { Bulk density of particles } \\ D_{t} & \text { Tapped density } \\ E D_{b} & \text { Bulk energy density } \\ \text { FC } & \text { Fixed carbon } \\ \text { FTIR } & \text { Fourier-transform infrared spectroscopy } \\ \text { GC } & \text { Gas chromatography } \\ \text { HHV } & \text { High heating value } \\ L \text { and } D_{p} & \text { Length and diameter of cylindrical acacia particles } \\ (L \times W \times H) & \text { Length, width and height dimensions for rectangular pine particles } \\ M C & \text { Moisture content } \\ \sum M_{p} & \text { Total particle mass } \\ M_{p} \text { and } V_{p} & \text { Mass and volume of the cylindrical particles } \\ \sum M_{t p} & \text { The total mass of tapped particles } \\ \text { SC } & \text { Supply chain } \\ \text { TGA } & \text { Thermogravimetric analyzer }\end{array}$

\section{References}

1. Álvarez-Álvarez, P. Evaluation of tree species for biomass energy production in Northwest Spain. Forests 2018, 9, 160. [CrossRef]

2. Amundson, J.; Sukumara, S.; Seay, J.; Badurdeen, F. Decision Support Models for Integrated Design of Bioenergy Supply Chains. Handb. Bioenergy 2015, 163-190. [CrossRef]

3. Eason, J.P.; Cremaschi, S. A multi-objective superstructure optimization approach to biofeedstocks-to-biofuels systems design. Biomass Bioenergy 2014, 63, 64-75. [CrossRef]

4. Braza, C.E.M.; Crnkovic, P.M. Physical-Chemical characterization of biomass samples for application in pyrolysis process. Chem. Eng. Trans. 2014, 37, 523-528. [CrossRef]

5. Feria, M.J. Energetic characterization of lignocellulosic biomass from Southwest Spain. Int. J. Green Energy 2011, 8, 631-642. [CrossRef] 
6. Mishra, R.K.; Mohanty, K. Thermal and catalytic pyrolysis of pine sawdust (Pinus ponderosa) and Gulmohar seed (Delonix regia) towards production of fuel and chemicals. Mater. Sci. Energy Technol. 2019, 2, 139-149. [CrossRef]

7. Naik, S.; Goud, V.V.; Rout, P.K.; Jacobson, K.; Dalai, A.K. Characterization of Canadian biomass for alternative renewable biofuel. Renew. Energy 2010, 35, 1624-1631. [CrossRef]

8. Núñez-Regueira, L.; Proupín-Castiñeiras, J.; Rodríguez-Añón, J.A. Energy evaluation of forest residues originated from shrub species in Galicia. Bioresour. Technol. 2004, 91, 215-221. [CrossRef]

9. Cai, J. Review of physicochemical properties and analytical characterization of lignocellulosic biomass. Renew. Sustain. Energy Rev. 2017, 76, 309-322. [CrossRef]

10. Charis, G.; Danha, G.; Muzenda, E. A critical taxonomy of socio-economic studies around biomass and bio-waste to energy projects. Detritus 2018, 3, 47-57. [CrossRef]

11. Tumuluru, J.S.; Tabil, L.G.; Song, Y.; Iroba, K.L.; Meda, V. ScienceDirect Grinding energy and physical properties of chopped and hammer-milled barley, wheat, oat, and canola straws. Biomass Bioenergy 2013, 60, 58-67. [CrossRef]

12. Mani, S.; Tabil, L.G.; Sokhansanj, S. Grinding performance and physical properties of wheat and barley straws, corn stover and switchgrass. Biomass Bioenergy 2004, 27, 339-352. [CrossRef]

13. Anukam, A.I.; Mamphweli, S.N.; Reddy, P.; Okoh, O.O. Characterization and the effect of lignocellulosic biomass value addition on gasification efficiency. Energy Explor. Exploit. 2016, 34, 865-880. [CrossRef]

14. Mamvura, T.A.; Pahla, G.; Muzenda, E. Torrefaction of waste biomass for application in energy production in South Africa. S. Afr. J. Chem. Eng. 2018, 25, 1-12. [CrossRef]

15. Lam, P.S. Physical characterization of wet and dry wheat straw and switchgrass-bulk and specific density. In Proceedings of the 2007 ASABE Annual International Meeting, Minneapolis, MN, USA, 17-20 June 2007; ASABE: St. Joseph, MI, USA, 2008; Volume 300.

16. Kirsanovs, V.; Blumberga, D.; Dzikevics, M.; Kovals, A. Design of Experimental Investigations on the Effect of Equivalence Ratio, Fuel Moisture Content and Fuel Consumption on Gasification Process. Energy Procedia 2016, 95, 189-194. [CrossRef]

17. Reza, S. Acacia Holosericea: An Invasive Species for Bio-char, Bio-oil, and Biogas Production. Bioengineering 2019, 6, 33. [CrossRef]

18. Charis, G.; Danha, G.; Muzenda, E. A review of timber waste utilization: Challenges and opportunities in Zimbabwe. Procedia Manuf. 2019, 35, 419-429. [CrossRef]

19. Effah, B.; Antwi, K.; Boampong, E.; Asamoah, J.N.; Asibey, O. The management and disposal of small scale sawmills residues at the Sokoban and Ahwia wood markets in Kumasi-Ghana. Int. J. Innov. Sci. Res. 2015, 19, 15-23.

20. Arimoro, F.O.; Ikomi, R.B.; Osalor, E.C. The impact of sawmill wood wastes on the water quality and fish communities of Benin River, Niger Delta area, Nigeria. World J. Zool. 2006, 1, 94-102.

21. Charis, G.; Danha, G.; Muzenda, E. Waste valorisation opportunities for bush encroacher biomass in savannah ecosystems: A comparative case analysis of Botswana and Namibia. Procedia Manuf. 2019, 35, 974-979. [CrossRef]

22. Acar, S.; Ayanoglu, A. Determination of higher heating values (HHVs) of biomass fuels. Uluslararası Yakıtlar Yanma Ve Yangin Dergisi 2016, 3, 1-3.

23. Krotz, L.; Giazzi, G. Elemental Analysis: CHNS/O Characterization of Biomass and Bio-fuels, 2017. Thermo Fischer Scientific. Available online: https:/assets.thermofisher.com/TFS-Assets/CMD/Application-Notes/an42151-oea-chnso-biomass-biofuels-an42151-en.pdf (accessed on 20 January 2019).

24. Liu, Y.; Zeng, F.; Sun, B.; Jia, P.; Graham, I.T. Structural Characterizations of Aluminosilicates in in Two Types of Fly Ash Samples from Shanxi Province, North China. Minerals 2019, 9, 358. [CrossRef]

25. Bridgwater, A.V. Review of fast pyrolysis of biomass and product upgrading. Biomass Bioenergy 2011, 38, 68-94. [CrossRef]

26. Olatunji, O.; Akinlabi, S.; Oluseyi, A.; Peter, M.; Madushele, N. Experimental investigation of thermal properties of Lignocellulosic biomass: A review. IOP Conf. Ser. Mater. Sci. Eng. 2018, 413, 012054. [CrossRef]

27. Ahmed, A.; Bakar, M.S.A.; Azad, A.K.; Sukri, R.S.; Phusunti, N. Intermediate pyrolysis of Acacia cincinnata and Acacia holosericea species for bio-oil and biochar production. Energy Convers. Manag. 2018, 176, $393-408$. [CrossRef]

28. MIT. FTIR Spectrophotometer. Qual Instrumentation; MIT: Cambridge, MA, USA, 2003; pp. 1-31. 
29. Spectroscopy DataTables, “Infrared Tables”. Available online: z:\%5Cfiles $\% 5$ Cclasses $\% 5$ Cspectroscopy $\%$ 5Ctypicalspectracharts.DOC (accessed on 20 January 2019).

30. Liu, C.; Wang, H.; Northwest, P.; Sun, J. Catalytic fast pyrolysis of lignocellulosic biomass. Chem. Soc. Rev. 2014, 43, 7594-7623. [CrossRef]

31. Dvorak, W.S.; Hodge, G.R.; Kietzka, J.E.; Malan, F.; Osorio, L.F.; Stanger, T.K. Pinus patula. In Conservation and Testing of Tropical and Subtropical Forest Tree Species by the CAMCORE Cooperative; CAMCORE: Raleigh, NC, USA, 2000; pp. 148-173.

32. Pratap, A.; Chouhan, S. Critical Analysis of Process Parameters for Bio-oil Production via Pyrolysis of Biomass: A Review. Recent Pat. Eng. 2013, 7, 98-114. [CrossRef]

33. DECOSA. Support to De-Bushing Project Value Added End-Use Opportunities for Namibian Encroacher Bush; DECOSA: Windhoek, Namibia, 2015.

34. Bridgwater, T. Challenges and Opportunities in Fast Pyrolysis of Biomass: Part I. Johns. Matthey Technol. Rev. 2018, 62, 118-130. [CrossRef]

(C) 2020 by the authors. Licensee MDPI, Basel, Switzerland. This article is an open access article distributed under the terms and conditions of the Creative Commons Attribution (CC BY) license (http://creativecommons.org/licenses/by/4.0/). 